\title{
The thermodynamics of ammonium scheelites. III. An analysis of the heat capacity and related data of deuterated ammonium perrhenate $\mathrm{ND}_{4} \mathrm{ReO}_{4}$
}

\author{
R. J. C. Brown \\ Department of Chemistry, Queen's University, Kingston, Ontario, K7L 3N6, Canada \\ J. E. Callanan \\ Center for Chemical Engineering, National Bureau of Standards, Boulder, Colorado 80303 \\ R. D. Weira) \\ Department of Chemistry and Chemical Engineering, Royal Military College of Canada, Kingston, \\ Ontario, K7K 5LO, Canada \\ E. F. Westrum, Jr. \\ Department of Chemistry, University of Michigan, Ann Arbor, Michigan 48109
}

(Received 29 May 1986; accepted 5 August 1986)

\begin{abstract}
An analysis of the heat capacity of deuterated and undeuterated $\mathrm{NH}_{4} \mathrm{ReO}_{4}$ has been carried out in which the effects of the anisotropy of the thermal expansion have been considered, an approach hitherto not used for ammonium compounds. In the ammonium scheelites, the axial thermal expansion coefficients are very large, but of opposite sign, and as a result the volume of the scheelite lattice is nearly independent of temperature. It is shown that the correction from constant stress to constant strain results in a major contribution to the heat capacity of this highly anisotropic lattice. The difference between the experimental and calculated values of heat capacity, referred to as $\Delta C_{p}$, is expressed as the sum of the contributions from the anisotropy and the rotational heat capacity. The results of the analysis show that the rotational contribution is much smaller then previously thought. However, the exact contribution of the anisotropy cannot be calculated at this time because the elastic constants are not known. In calculating the heat capacity, maximum use has been made of external optical mode frequencies derived from spectroscopic measurements.
\end{abstract}

\section{INTRODUCTION}

Thermodynamic properties provide a rigorous test of theories of the dynamics of solids. In the case of ammonium salts, it is not unusual to find a broad peak in the graph of heat capacity vs temperature which is not present for the alkali metal salts of the same anion. The origin of the peak is thought to be the rotational energy levels of the ammonium ion, which can be computed from quantum theory if the rotational potential energy function of the ammonium ion is known or assumed.

The reliability of heat capacity data as a test of theoretical models for the rotation of the ammonium ion depends upon being able accurately to separate the ammonium ion rotational heat capacity from various other contributions to the measured heat capacity. The rotational contribution is a small part of the total heat capacity, and so any uncertainty in other contributions drastically reduces the reliability of the "experimental" value of the rotational heat capacity.

Ammonium perrhenate, $\mathrm{NH}_{4} \mathrm{ReO}_{4}$, provides an excellent test of the analysis procedures. The heat capacities of $\mathrm{KReO}_{4}$ and $\mathrm{NH}_{4} \mathrm{ReO}_{4}$ have been measured and analyzed previously. 'The rotational heat capacity peak in $\mathrm{NH}_{4} \mathrm{ReO}_{4}$ deduced from such an analysis is larger than that of any other known peak, ${ }^{2}$ and no adequate explanation in terms of the ammonium ion rotational motion has been published to date. To elucidate this problem, the heat capacity of $\mathrm{ND}_{4} \mathrm{ReO}_{4}$ was recently measured. ${ }^{3}$ In attempting to under-

\footnotetext{
a) Author to whom correspondence should be sent.
}

stand these and the previous results, the method of analysis used formerly has been reexamined and revised in this paper designated III in the series of our continuing study on the scheelites. Previous papers are designated $\mathrm{I}^{1}$ and $\mathrm{II}^{3}$.

In the present analysis of the heat capacity of both deuterated and undeuterated $\mathrm{NH}_{4} \mathrm{ReO}_{4}$ the effect of the anisotropy of the thermal expansion has been considered. In ammonium perrhenate, the axial thermal expansion coefficients are very large, but of opposite sign, and the volume is almost independent of temperature. ${ }^{4,5}$ In this paper the effects of this gross anisotropy are considered and shown to be a major contributor to the heat capacity; the exact contribution cannot be calculated because the elastic constants are not known. A revised procedure for the analysis of heat capacity data is used, in which maximum use is made of known spectroscopic data. It appears that the rotational heat capacity peak is much smaller than was previously thought.

\section{ANISOTROPIC THERMAL EXPANSION}

For an isotropic material, the contribution of thermal expansion to the heat capacity at constant pressure $C_{p}$ is described by the standard equation

$$
C_{p}-C_{v}=V T \alpha^{2} / \kappa_{T},
$$

where $\alpha=V^{-1}(\partial V / \partial T)_{P}$ is the volume thermal expansion coefficient, $V$ is the molar volume, and $K_{T}=-V^{-1}(\partial V /$ $\partial P)_{T}$ is the isothermal compressibility. Heat capacities calculated from quantum energy levels through statistical mechanics usually refer to constant volume conditions. For 
ammonium ions in a noncubic crystal with atoms in general positions, the calculations are normally made under very restrictive "constant geometry" conditions in which the atoms in the vicinity of each ammonium ion are held at constant positions relative to the ammonium ion, independent of temperature. This requires that the unit cell dimensions and angles, and all atomic position parameters other than those of the hydrogen atoms in the ammonium ion, be kept constant. In order to use the results of statistical mechanics in analyzing observed heat capacity data, the measured $C_{p}$ values must be corrected to constant geometry. Only for cubic crystals with all atoms in special positions does constant geometry correspond to constant volume.

Changes in the unit cell dimensions and angles correspond to elastic strains, and are related to stresses on the crystal through the elastic constants. Elastic strain and the corresponding stress are subject to thermodynamic analysis, but the atomic position parameters correspond to "internal strain" which cannot be changed by the application of any external stress. ${ }^{6}$ Therefore the best that can be achieved by a thermodynamic description is a calculation of the heat capacity of a model constrained to constant unit cell dimensions and angles, i.e., the heat capacity at constant strain.

The relationship between the heat capacities at constant stress $C_{\sigma}$ and constant strain $C_{\epsilon}$ for an anisotropic crystal is an extension of Eq. (1) $)^{7,8}$ :

$$
C_{\sigma}-C_{\epsilon}=V T \sum c_{i j k l} \alpha_{i j} \alpha_{k l},
$$

in which $c_{i j k l}$ is the isothermal elastic constant tensor and $\alpha_{i j}$ is the thermal expansion tensor. For the present purposes, the condtion of constant stress means constant pressure. For the case of the scheelite structure with tetragonal symmetry, the last equation becomes, in Voigt notation,

$$
C_{p}-C_{\epsilon}=V T\left\{\left(2 c_{11}+c_{12}\right) \alpha_{1}^{2}+2 c_{13} \alpha_{1} \alpha_{3}+c_{33} \alpha_{3}^{2}\right\}
$$

Thus $C_{p}-C_{\epsilon}$ is quadratic in the diagonal components of the thermal expansion tensor $\alpha$, and can be large even in a situation where the bulk thermal expansion (i.e., the trace of $\alpha$ ) is small, as for the ammonium scheelites. The thermal expansion tensor for ammonium perrhenate is known in detail over a wide temperature range, ${ }^{4,5}$ but the elastic constant tensor is not known at any temperature, so the right-hand side of Eq. (3) cannot be evaluated numerically at present.

Shown in Fig. 1 are the two diagonal components of the thermal expansion tensor of the $\mathrm{NH}_{4} \mathrm{ReO}_{4}$ as a function of temperature. These curves were determined by fitting a polynomial to the unit cell data, 4,5 and then differentiating the polynomial. Below about $100 \mathrm{~K}$, both thermal expansion coefficients are small and positive, but from that temperature to $300 \mathrm{~K}, \alpha_{1}\left(\alpha_{a}\right)$ and $\alpha_{3}\left(\alpha_{c}\right)$ are of opposite sign, and become numerically large near $200 \mathrm{~K}$. Therefore $C_{p}-C_{\epsilon}$ must have a maximum in the vicinity of $200 \mathrm{~K}$, unless the elastic constant tensor $c$ has a very strong temperature dependence.

The magnitude of $C_{p}-C_{\epsilon}$ can be estimated from Eq. (3) if estimates of the elastic constants are made based upon published data for related crystals. ${ }^{9}$ For instance, the diagonal components of the elastic constant tensor for ammonium sulphate are close to $30 \mathrm{GPa}$, and if this value is used for $c_{33}$ in Eq. (3), together with the molar volume of $\mathrm{NH}_{4} \mathrm{ReO}_{4}$, $6.7 \times 10^{-5} \mathrm{~m}^{3} \mathrm{~mol}^{-1}$, the contribution of the last term in braces to $C_{p}-C_{\epsilon}$ is found to be approximately 40 $\mathrm{J} \mathrm{K}^{-1} \mathrm{~mol}^{-1}$ in the vicinity of $200 \mathrm{~K}$. Some cancellation can be expected due to the negative cross term in $\alpha_{1} \alpha_{3}$, but even so, it is clear that $C_{p}-C_{\epsilon}$ is likely to very much larger than the previous estimates ${ }^{1}$ of $C_{p}-C_{v}$ made using Eq. (1). These were $5.1 \mathrm{~J} \mathrm{~K}^{-1} \mathrm{~mol}^{-1}$ at $300 \mathrm{~K}_{\text {for }} \mathrm{KReO}_{4}$, and 1.3 $\mathrm{J} \mathrm{K}^{-1} \mathrm{~mol}^{-1}$ at $300 \mathrm{~K}$ for $\mathrm{NH}_{4} \mathrm{ReO}_{4}$. Further, because of the temperature dependence of $\alpha_{1}$ and $\alpha_{3}, C_{p}-C_{\epsilon}$ is peaked at about $200 \mathrm{~K}$ and may be responsible for a large part of the observed broad peak in $C_{p}$.

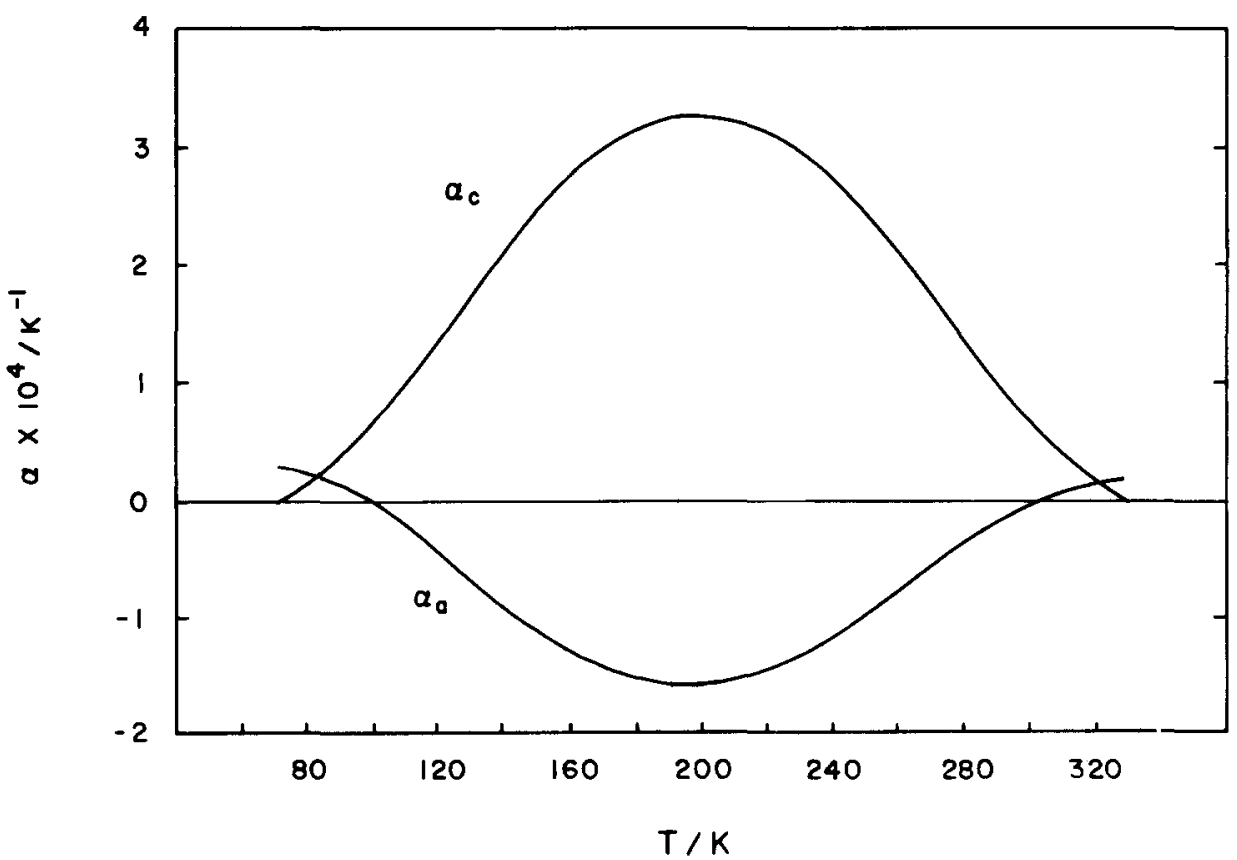

FIG. 1. Thermal expansion coefficients $\alpha_{a}$, $\alpha_{c}$ for $\mathrm{NH}_{4} \mathrm{ReO}_{4}$. 
TABLE I. Assignments of spectroscopic frequency $v$ in $\mathrm{cm}^{-1}$.

\begin{tabular}{|c|c|c|c|c|c|c|c|c|}
\hline \multicolumn{9}{|c|}{$\mathrm{ReO}_{4}^{-}$internal modes } \\
\hline $\begin{array}{l}\mathrm{KReO}_{4} \\
\mathrm{NH}_{4} \mathrm{ReO}_{4} \\
\mathrm{ND}_{4} \mathrm{ReO}_{4}\end{array}$ & $\begin{array}{c}A_{g}+B_{u} \\
966 \\
969 \\
969\end{array}$ & $\begin{array}{c}A_{g}+B_{u} \\
350 \\
335 \\
335\end{array}$ & $\begin{array}{c}B_{g}+A_{u} \\
350 \\
328 \\
328\end{array}$ & $\begin{array}{c}B_{\mathbf{g}}+A_{u} \\
924 \\
910 \\
910\end{array}$ & $\begin{array}{c}E_{g}+E_{u} \\
897 \\
893 \\
893\end{array}$ & $\begin{array}{c}B_{g}+A_{\mu} \\
332 \\
351 \\
351\end{array}$ & $\begin{array}{c}E_{g}+E_{u} \\
337 \\
351 \\
351\end{array}$ & \\
\hline \multicolumn{9}{|c|}{$\mathrm{NH}_{4}{ }^{+}$internal modes } \\
\hline $\begin{array}{l}\mathrm{NH}_{4} \mathrm{ReO}_{4} \\
\mathrm{ND}_{4} \mathrm{ReO}_{4}\end{array}$ & $\begin{array}{c}A_{g}+B_{u} \\
3128 \\
2258\end{array}$ & $\begin{array}{c}A_{g}+B_{u} \\
1658 \\
1198\end{array}$ & $\begin{array}{c}B_{g}+A_{u} \\
1658 \\
1191\end{array}$ & $\begin{array}{c}B_{g}+A_{u} \\
3182 \\
2382\end{array}$ & $\begin{array}{c}E_{g}+E_{u} \\
3182 \\
2382\end{array}$ & $\begin{array}{c}B_{g}+A_{u} \\
1438 \\
1081\end{array}$ & $\begin{array}{c}E_{g}+E_{u} \\
1431 \\
1081\end{array}$ & \\
\hline \multicolumn{9}{|c|}{ External modes } \\
\hline & $A_{g}$ & $E_{8}$ & $E_{g}$ & $B_{g}$ & $E_{\mathrm{g}}$ & $B_{g}$ & $E_{g}+E_{u}$ & $A_{g}+B_{u}$ \\
\hline $\begin{array}{l}\mathrm{KreO}_{4} \\
\mathrm{NH}_{4} \mathrm{ReO}_{4} \\
\mathrm{ND}_{4} \mathrm{ReO}_{4}\end{array}$ & $\begin{array}{l}127.9 \\
135.3 \\
134.5\end{array}$ & $\begin{array}{l}114.4 \\
120.3 \\
117.1\end{array}$ & $\begin{array}{l}72.5 \\
67.6 \\
66.9\end{array}$ & $\begin{array}{l}59.1 \\
49.3 \\
48.6\end{array}$ & $\begin{array}{l}160.1 \\
210.1 \\
193.7\end{array}$ & $\begin{array}{l}151 \\
189.7 \\
174.2\end{array}$ & $\begin{array}{c}\ldots \\
272 \\
203\end{array}$ & $\begin{array}{c}\ldots \\
263.3 \\
193.7\end{array}$ \\
\hline $\mathrm{ND}_{4} \mathrm{ReO}_{4}$ & $A_{u}$ & $E_{u}$ & $E_{u}$ & $B_{u}$ & & & & \\
\hline $\begin{array}{l}\mathrm{KReO}_{4} \\
\mathrm{NH}_{4} \mathrm{ReO}_{4} \\
\mathrm{ND}_{4} \mathrm{ReO}_{4}\end{array}$ & $\begin{array}{r}90 \\
108 \\
106\end{array}$ & $\begin{array}{l}125 \\
134 \\
140\end{array}$ & $\begin{array}{l}158 \\
170 \\
169\end{array}$ & $\begin{array}{l}\mathrm{a} \\
\mathrm{a} \\
\mathrm{a}\end{array}$ & & & & \\
\hline
\end{tabular}

Unassigned.

\section{ANALYSIS OF HEAT CAPACITY DATA}

The heat capacity data for $\mathrm{KReO}_{4}$ and $\mathrm{NH}_{4} \mathrm{ReO}_{4}$, which have already been published, will be treated first, as a check on the consistency of the revised procedure. Then the new data on $\mathrm{ND}_{4} \mathrm{ReO}_{4}$ will be analyzed. form

The experimental heat capacity $C_{\exp }$ is written in the

$$
C_{\text {exp }}=\left(C_{p}-C_{\epsilon}\right)+C_{\text {vib }}+C_{\text {lat }}+C_{\text {rot }},
$$

where $C_{\text {vib }}$ is the heat capacity derived from known vibrational frequencies at $77 \mathrm{~K}$, including internal modes of both ions, and external modes except for the ammonium ion rotational or librational modes; $C_{\text {lat }}$ is the heat capacity for the acoustic modes; and, in the case of the ammonium salts, $C_{\text {rot }}$ represents the rotational heat capacity corresponding to the ammonium ion librational or rotational motion. Since frequencies at a fixed temperature are used for the calculation of $C_{\text {vib }}$, this quantity is, in effect, a heat capacity at constant geometry.

The quantity actually measured calorimetrically is $C_{\text {sat }}$, the heat capacity of the solid or liquid in equilibrium with its saturated vapor. This is related to $C_{p}$ by

$$
C_{\text {sat }}-C_{p}=\left(\frac{\partial P}{\partial T}\right)_{\text {sat }}\left[\left(\frac{\partial H}{\partial P}\right)_{T}-V\right] \text {. }
$$

For the solid scheelites, $C_{\mathrm{sat}}-C_{p}$ is negligible.

The space group of the scheelite structure is $I 4_{1} / a$ or No. $88 C_{4 h}^{6}$ with four formula units per crystallographic unit cell and two formula units per primitive cell. $\mathrm{KReO}_{4}$ has 36 unit cell vibrations which can be classified as $2 A_{g}+3 B_{g}+2 E_{g}+3 A_{u}+2 B_{u}+2 E_{u}$ internal modes, $A_{g}+2 B_{g}+3 E_{g}+A_{u}+B_{u}+2 E_{u}$ external modes, and $A_{u}+E_{u}$ acoustic modes. ${ }^{10} \mathrm{NH}_{4} \mathrm{ReO}_{4}$ has 60 unit cell vibrations which can be classified as $4 A_{g}+6 B_{g}$ $+4 E_{g}+6 A_{u}+4 B_{u}+4 E_{u}$ internal modes, $2 A_{g}+2 B_{g}+4 E_{g}+A_{u}+2 B_{u}+3 E_{u}$ external modes, and $A_{u}+E_{u}$ acoustic modes. ${ }^{11}$ The assignments and wave numbers are summarized in Table I.

The assignments of the $g$ mode frequencies of both internal and external modes based upon Raman spectra ${ }^{10-14}$ have been used. The $u$ internal modes have been assumed to have the same frequencies as the corresponding $g$ modes and, because these frequencies are high, no serious error is introduced by this procedure. Assignment of the $u$ external modes is more tentative. The $B_{u}$ modes are inactive in both IR and Raman spectra. Some information about the other modes has been obtained from IR spectra, ${ }^{15}$ but the assignment of the frequencies is uncertain. Details of the assignments will be given in the sections to follow.

The first step in the analysis is to compute $C_{\text {vib }}$ from spectroscopic data at low temperatures, including translational external modes for both ions and librational external modes for the anion. At low temperatures, the rotational motion of the ammonium ion manifests itself in the Raman spectrum as well-defined librational modes. Hence for temperatures below $120 \mathrm{~K}, C_{\text {rot }}$ is replaced by the librational heat capacity $C_{\text {lib }}$, which is calculated using the Einstein function with the observed low temperature librational frequencies of the ammonium ion. At low temperatures, the contribution of thermal expansion to the heat capacity is very small, so $C_{\text {exp }}-C_{\text {vib }}-C_{\text {lib }}$ at low temperature is dominated by the heat capacity of the acoustic modes. The low temperature values of $C_{\text {exp }}-C_{\text {vib }}-C_{\text {lib }}$ were therefore fitted to a Debye function corresponding to three acoustic degrees of freedom per unit cell containing two formula units.

If the Debye model were obeyed, the $\theta_{D}(T)$ should be constant for any crystal. However for real crystals, the model does not describe what is observed experimentally. For many metal and diatomic lattices, $\theta_{D}(T)$ asymptotically approaches a constant value at high temperatures where all the modes of vibration contribute to the heat capacity. For other crystals, $\theta_{D}(T)$ rises as temperature increases, reaches a maximum and then falls. To obtain the contribution of the 


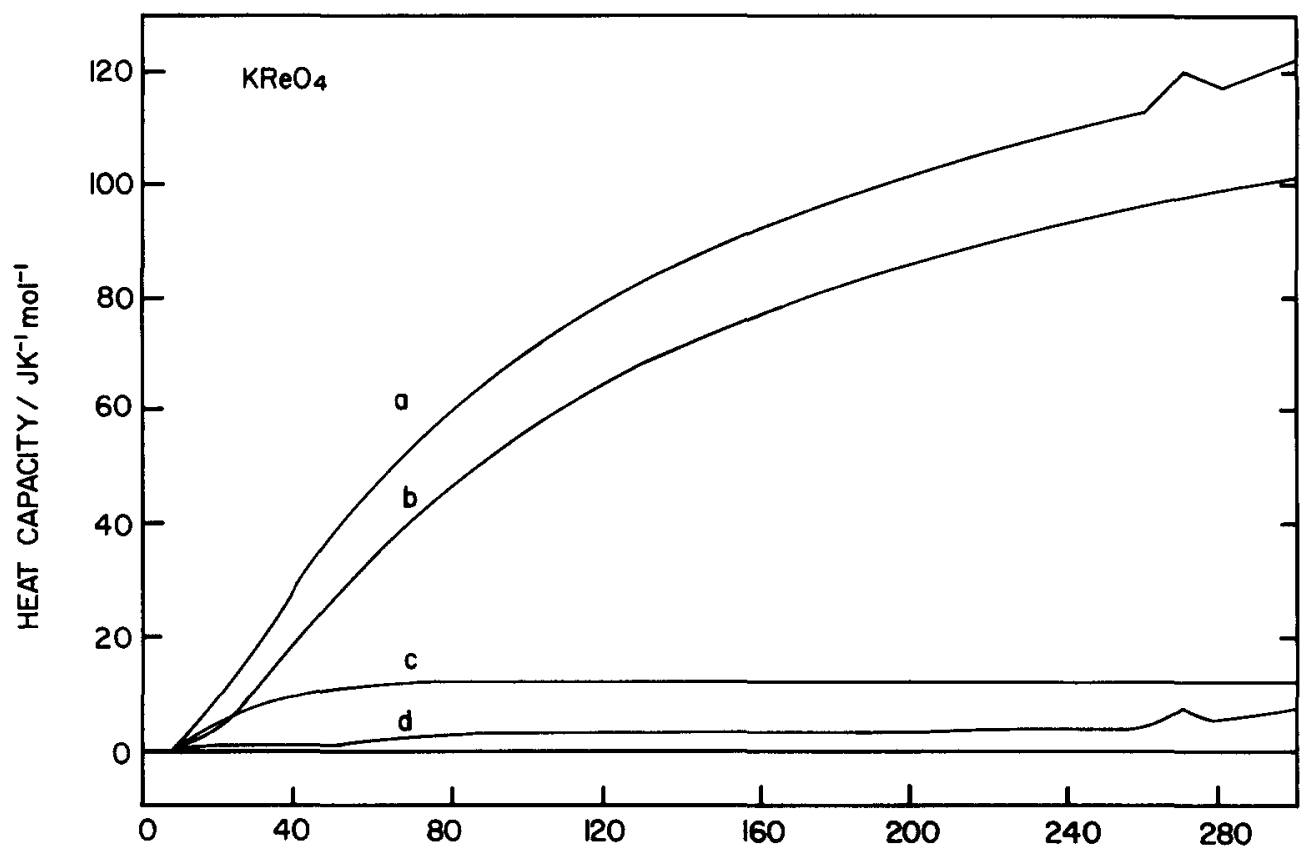

FIG. 2. Molar heat capacity of $\mathrm{KReO}_{4}$. Curves: $\mathrm{a}=$ experimental (Ref. 1), b = vibrational contribution from internal + external optical modes, $c=$ lattice contribution (Debye heat capacity for acoustic modes), $\mathrm{d}=$ residual heat capacity $C_{\text {resid }}=C_{\text {exp }}-C_{\text {vib }}-C_{\text {lat }}=\left(C_{p}\right.$ $-C_{\epsilon}$ ) (see the text for full discussion of vibrational and lattice contributions)

$T / K$

lattice vibrations to the heat capacity in these crystals, the $\theta_{D}(T)$ is plotted and the asymtotic value at the peak $\theta_{D}^{\infty}$ is drawn to extend to high temperatures. The resulting curve is then used in conjunction with Debye tables. At temperatures below the point where $\theta_{D}^{\infty}$ is reached, values of $\theta_{D}$ based on experimental heat capacities were used to obtain $C_{\text {lat }}$. Then by difference, $C_{p}-C_{\epsilon}+C_{\mathrm{rot}}$ is calculated over the whole temperature range.

\section{A. $\mathrm{KReO}_{4}$}

All internal modes and the external $g$ modes were assigned frequencies from the literature. ${ }^{11,13,14}$ Two IR frequencies ${ }^{15}$ were assigned as $E_{u}$ and an unobserved frequency was assigned $A_{u}$ and estimated as $90 \mathrm{~cm}^{-1}$ by comparison with corresponding spectra of $\mathrm{NaReO}_{4}$ and $\mathrm{RbReO}_{4}$. With these assignments, $C_{\text {vib }}$ was calculated as a sum of Einstein functions, including a factor for degeneracy, to include the 18 internal degrees of freedom and 14 of the 18 external modes, the 3 external acoustic modes being considered separately as the acoustic lattice modes. The remaining inactive $B_{u}$ external mode was placed with the $C_{\text {vib }}$ by multiplying the external heat capacity by $15 / 14$.

The difference $C_{\text {exp }}-C_{\text {vib }}$ was then computed, and the data for low temperatures were fitted to a Debye function for 1.5 degrees of freedom per mole, corresponding to the three acoustic modes per unit cell containing two formula units. The value of the Debye $\theta_{D}^{\infty}$ was $94.4 \mathrm{~K}$, and this value was then used to calculate the lattice heat capacity over the entire temperature range.

The residual heat capacity $C_{\text {resid }}=C_{\text {exp }}-C_{\text {vib }}-C_{\text {lat }}$ is just $C_{p}-C_{\epsilon}$, as there is no rotational heat capacity in the potassium salt. The resuts of this analysis are shown in Fig. 2 and Table II. The peak near $270 \mathrm{~K}$ results from the fusion of water and should be ignored. Apart from the effects of this slight water contamination above $270 \mathrm{~K}$, the limiting high temperature value of $C_{\text {resid }}$ is $4.3 \mathrm{~J} \mathrm{~K}^{-1} \mathrm{~mol}^{-1}$, (Table II) which agrees well with the value $5.1 \mathrm{~J} \mathrm{~K}^{-1} \mathrm{~mol}^{-1}$ estimated for $C_{p}-C_{v}{ }^{1}$ This shows that all degrees of freedom have been satisfactorily accounted for. The thermal expansion tensor in $\mathrm{KReO}_{4}$ is only slightly anistropic. ${ }^{4}$

\section{B. $\mathrm{NH}_{4} \mathrm{ReO}_{4}$}

All internal modes and the external $g$ modes were assigned frequencies from the literature. ${ }^{10-12}$ Values at $77 \mathrm{~K}$ or lower were used and the frequencies were kept constant in calculating their contributions to the heat capacity, since the contributions of the vibrational modes at constant geometry are required. The external mode frequencies are quite strongly dependent on temperature. ${ }^{10,11}$ Three IR wave numbers ${ }^{15}$ of 108,134 , and $170 \mathrm{~cm}^{-1}$ were assigned as $A_{u}, E_{u}$, and $E_{u}$ respectively. With these frequency assignments, $C_{\text {vib }}$ was calculated as a sum of Einstein functions to include the 36 internal modes and 14 of the 24 external modes. An inactive $B_{u}$ mode was then incorporated with the internal modes by multiplying the external heat capacity by $15 / 14$. The low temperature librational frequencies of 272 and $263.3 \mathrm{~cm}^{-1}$ for the ammonium ion were used to calculate $C_{\mathrm{lib}}$ at low temperatures corresponding to their six degrees of freedom.

The difference $C_{\text {exp }}-C_{\text {vib }}-C_{\text {lib }}$ was then computed, and the data for low temperatures were fitted to a Debye function for 1.5 degrees of freedom per mole, corresponding to the three acoustic modes per unit cell containing two formula units. The value of the Debye $\theta_{D}^{\infty}$ was $81.8 \mathrm{~K}$, and this value was then used to calculate the lattice heat capacity over the entire temperature range above $30 \mathrm{~K}$.

The residual heat capacity $C_{\text {resid }}=C_{\text {exp }}-C_{\text {vib }}-C_{\text {lat }}$ is equal to $\left(C_{p}-C_{\epsilon}\right)+C_{\text {rot }}$, and is plotted against temperature in Fig. 3 and Table III. The kink near $270 \mathrm{~K}$ results because of the slight water impurity. 
TABLE II. Heat capacity analysis for $\mathrm{KReO}_{4}, C_{\text {exp }}$, smoothed experimental molar heat capacity; $C_{\text {vib }}$, estimated vibrational contribution from all internal + external optical modes; $C_{\text {lat }}$, lattice contribution (Debye heat capacity for acoustic modes) $C_{\text {resid }}=C_{\text {exp }}-C_{\text {vib }}-C_{\text {lat }}=\left(C_{p}-C_{\epsilon}\right)$.

\begin{tabular}{|c|c|c|c|c|c|}
\hline $\begin{array}{c}T \\
(\mathbf{K})\end{array}$ & $\begin{array}{c}C_{\exp } \\
\left(\mathrm{J} \mathrm{K}^{-1} \mathrm{~mol}^{-1}\right)\end{array}$ & $\underset{\left(\mathrm{J} \mathrm{K}^{-1} \mathrm{~mol}^{-1}\right)}{C_{\mathrm{vib}}}$ & $\begin{array}{c}C_{\exp }-C_{\text {vib }} \\
\left(\mathrm{J} \mathrm{K} \mathrm{K}^{-1} \mathrm{~mol}^{-1}\right)\end{array}$ & $\begin{array}{c}C_{\text {lat }} \\
\left(\mathrm{J} \mathrm{K}^{-1} \mathrm{~mol}^{-1}\right)\end{array}$ & $\begin{array}{c}C_{\text {resid }} \\
\left(\mathrm{J} \mathrm{K}^{-1} \mathrm{~mol}^{-1}\right)\end{array}$ \\
\hline 10 & 1.20 & 0.10 & 1.10 & 1.11 & 0.00 \\
\hline 20 & 9.00 & 3.12 & 5.88 & 5.03 & 0.85 \\
\hline 30 & 18.60 & 10.01 & 8.59 & 7.96 & 0.63 \\
\hline 40 & 28.70 & 18.38 & 10.32 & 9.59 & 0.73 \\
\hline 50 & 37.90 & 26.48 & 11.42 & 10.50 & 0.91 \\
\hline 60 & 46.00 & 33.72 & 12.28 & 11.06 & 1.23 \\
\hline 70 & 53.20 & 40.13 & 13.07 & 11.41 & 1.67 \\
\hline 80 & 59.60 & 45.88 & 13.72 & 11.65 & 2.07 \\
\hline 90 & 65.25 & 51.11 & 14.14 & 11.81 & 2.32 \\
\hline 100 & 70.40 & 55.89 & 14.51 & 11.93 & 2.58 \\
\hline 110 & 75.00 & 60.24 & 14.76 & 12.02 & 2.74 \\
\hline 120 & 79.20 & 64.20 & 15.00 & 12.09 & 2.91 \\
\hline 130 & 82.95 & 67.81 & 15.14 & 12.15 & 3.00 \\
\hline 140 & 86.30 & 71.09 & 15.21 & 12.19 & 3.02 \\
\hline 150 & 89.25 & 74.09 & 15.16 & 12.23 & 2.93 \\
\hline 160 & 92.20 & 76.85 & 15.35 & 12.26 & 3.09 \\
\hline 170 & 94.80 & 79.40 & 15.40 & 12.28 & 3.12 \\
\hline 180 & 97.25 & 81.76 & 15.49 & 12.30 & 3.19 \\
\hline 190 & 99.70 & 83.97 & 15.73 & 12.32 & 3.41 \\
\hline 200 & 102.00 & 86.04 & 15.96 & 12.33 & 3.62 \\
\hline 210 & 104.10 & 88.00 & 16.10 & 12.35 & 3.75 \\
\hline 220 & 106.20 & 89.85 & 16.35 & 12.36 & 3.99 \\
\hline 230 & 108.00 & 91.62 & 16.38 & 12.37 & 4.02 \\
\hline 240 & 109.70 & 93.30 & 16.40 & 12.38 & 4.03 \\
\hline 250 & 111.40 & 94.90 & 16.50 & 12.38 & 4.11 \\
\hline 260 & 113.10 & 96.44 & 16.66 & 12.39 & 4.27 \\
\hline 270 & 120.20 & 97.91 & 22.29 & 12.40 & 9.89 \\
\hline 280 & 117.60 & 99.32 & 18.28 & 12.40 & 5.87 \\
\hline 290 & 119.80 & 100.68 & 19.12 & 12.41 & 6.72 \\
\hline 300 & 122.40 & 101.97 & 20.43 & 12.41 & 8.02 \\
\hline
\end{tabular}

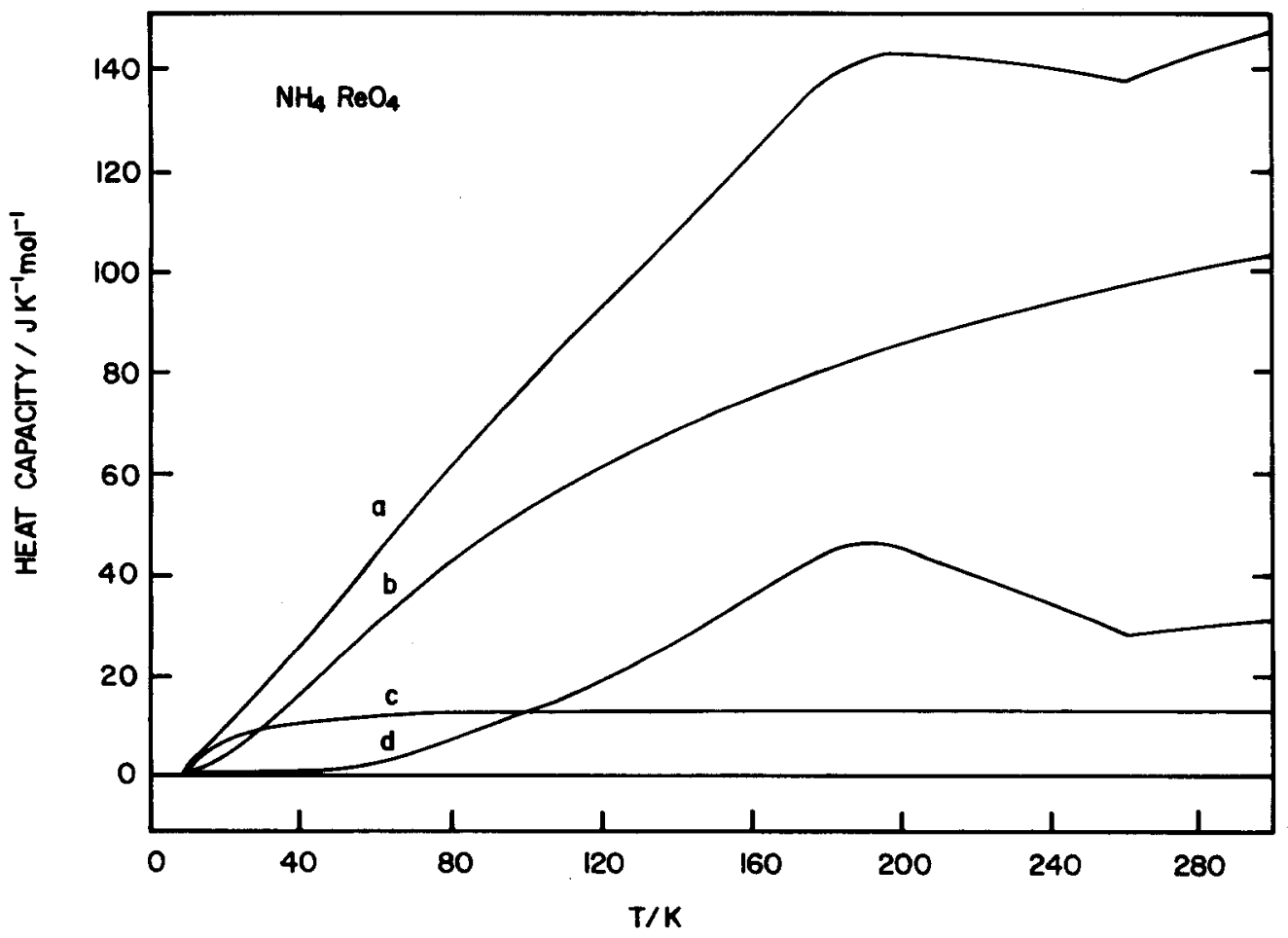

FIG. 3. Molar heat capacity of $\mathrm{NH}_{4} \mathrm{ReO}_{4}$. Curves: $\mathrm{a}=$ experimental (Ref. 1), b = vibrational contribution from internal + external optical modes of $\mathrm{NH}_{4}^{+}$and $\mathrm{ReO}_{4}^{-}$ and librational from external modes of $\mathrm{ReO}_{4}^{-}, \mathrm{c}=$ lattice contribution from $\mathrm{NH}_{4}^{+}$and $\mathrm{ReO}_{4}^{-}$(Debye heat capacity for acoustic modes), $\mathrm{d}=$ residual heat capacity $C_{\text {resid }}$ $=C_{\text {exp }}-C_{\text {vib }}-C_{\text {lat }}=\left(C_{p}-C_{\epsilon}\right)$ $+C_{\text {rot }}$ (see the text for full discussion of vibrational and lattice contributions). 
TABLE III. Heat capacity analysis for $\mathrm{NH}_{4} \mathrm{ReO}_{4} . C_{\text {exp }}$ smoothed experimental molar heat capacity; $C_{\text {vib }}$, estimated contribution from internal optical modes of $\mathrm{NH}_{4}{ }^{+}$and $\mathrm{ReO}_{4}{ }^{-}$ions and all external optical modes except librational modes of $\mathrm{NH}_{4}{ }^{+} ; C_{\text {lib }}$, contribution from librational modes of $\mathrm{NH}_{4}{ }^{+}$ions; $C_{\text {lat }}$, lattice contribution from $\mathrm{NH}_{4}{ }^{+}$and $\mathrm{ReO}_{4}{ }^{-}$(Debye heat capacity for acoustic modes) $C_{\text {resid }}=C_{\text {exp }}-C_{\text {vib }}-C_{\text {lat }}=C_{p}-C_{\epsilon}+C_{\text {rot }}$ (see the text).

\begin{tabular}{|c|c|c|c|c|c|c|}
\hline $\begin{array}{c}T \\
(\mathbf{K})\end{array}$ & $\begin{array}{c}C_{\exp } \\
\left(\mathrm{J} \mathrm{K}^{-1} \mathrm{~mol}^{-1}\right)\end{array}$ & $\begin{array}{c}C_{\mathrm{vib}} \\
\left(\mathrm{J} \mathrm{K}^{-1} \mathrm{~mol}^{-1}\right)\end{array}$ & $\begin{array}{c}C_{\mathrm{lib}} \\
\left(\mathrm{J} \mathrm{K}^{-1} \mathrm{~mol}^{-1}\right)\end{array}$ & $\begin{array}{c}C_{\mathrm{exp}}-C_{\mathrm{vib}}-C_{\mathrm{lib}} \\
\left(\mathrm{J} \mathrm{K}^{-1} \mathrm{~mol}^{-1}\right)\end{array}$ & $\begin{array}{c}C_{\mathrm{lat}} \\
\left(\mathrm{J} \mathrm{K}^{-1} \mathrm{~mol}^{-1}\right)\end{array}$ & $\begin{array}{c}C_{\text {resid }} \\
\left(\mathrm{J} \mathrm{K}^{-1} \mathrm{~mol}^{-1}\right)\end{array}$ \\
\hline 10 & 1.48 & 0.24 & 0.00 & 1.24 & 1.24 & 0.00 \\
\hline 20 & 10.20 & 3.68 & 0.00 & 6.52 & 6.52 & 0.00 \\
\hline 30 & 18.40 & 9.56 & 0.01 & 8.83 & 8.83 & 0.01 \\
\hline 40 & 26.90 & 16.49 & 0.15 & 10.26 & 10.21 & 0.20 \\
\hline 50 & 35.70 & 23.55 & 0.65 & 11.50 & 10.95 & 1.20 \\
\hline 60 & 43.70 & 30.26 & 1.64 & 11.80 & 11.39 & 2.06 \\
\hline 70 & 52.10 & 36.53 & 3.05 & 12.52 & 11.66 & 3.91 \\
\hline 80 & 60.80 & 42.37 & 4.70 & 13.73 & 11.84 & 6.59 \\
\hline 90 & 69.60 & 47.80 & 6.42 & 15.38 & 11.97 & 9.83 \\
\hline 100 & 76.80 & 52.81 & 8.12 & 15.87 & 12.06 & 11.92 \\
\hline 110 & 85.00 & 57.42 & 9.71 & 17.87 & 12.13 & 15.45 \\
\hline 120 & 93.00 & 61.63 & 11.18 & 20.20 & 12.19 & 19.19 \\
\hline 130 & 100.50 & 65.46 & $\ldots$ & $\ldots$ & 12.23 & 22.81 \\
\hline 140 & 107.70 & 68.96 & $\ldots$ & $\ldots$ & 12.26 & 26.47 \\
\hline 150 & 115.00 & 72.16 & $\ldots$ & $\cdots$ & 12.29 & 30.55 \\
\hline 160 & 122.70 & 75.10 & $\cdots$ & $\cdots$ & 12.31 & 35.29 \\
\hline 170 & 130.40 & 77.81 & $\cdots$ & $\ldots$ & 12.33 & 40.26 \\
\hline 180 & 136.40 & 80.34 & $\ldots$ & $\ldots$ & 12.34 & 43.72 \\
\hline 190 & 141.40 & 82.70 & $\ldots$ & $\cdots$ & 12.36 & 46.34 \\
\hline 200 & 142.80 & 84.93 & $\ldots$ & $\ldots$ & 12.37 & 45.50 \\
\hline 210 & 142.00 & 87.04 & $\ldots$ & $\ldots$ & 12.38 & 42.58 \\
\hline 220 & 140.90 & 89.06 & ... & $\ldots$ & 12.39 & 39.46 \\
\hline 230 & 139.90 & 91.00 & $\ldots$ & $\ldots$ & 12.39 & 36.51 \\
\hline 240 & 139.20 & 92.86 & $\ldots$ & $\ldots$ & 12.40 & 33.94 \\
\hline 250 & 138.50 & 94.67 & $\cdots$ & $\ldots$ & 12.41 & 31.42 \\
\hline 260 & 136.50 & 96.43 & $\ldots$ & $\ldots$ & 12.41 & 27.66 \\
\hline 270 & 139.50 & 98.14 & $\ldots$ & $\ldots$ & 12.41 & 28.95 \\
\hline 280 & 141.30 & 99.81 & $\cdots$ & $\cdots$ & 12.42 & 29.07 \\
\hline 290 & 144.00 & 101.44 & $\cdots$ & $\ldots$ & 12.42 & 30.13 \\
\hline 300 & 146.90 & 103.04 & $\ldots$ & $\ldots$ & 12.43 & 31.43 \\
\hline
\end{tabular}

\section{C. $\mathrm{ND}_{4} \mathrm{ReO}_{4}$}

The same procedure was followed for the deuterated salt. An unobserved $E_{8}$ librational mode of the $\mathrm{ND}_{4}^{+}$ion was estimated as $203 \mathrm{~cm}^{-1}$ by comparison with the recently reported spectrum of the undeuterated salt at $10 \mathrm{~K} .{ }^{12}$ The value of the Debye $\theta_{D}^{\infty}$ was $75.4 \mathrm{~K}$. The results of the analysis are shown in Fig. 4 and Table IV.

\section{DISCUSSION}

The residual heat capacities $C_{\text {resid }}$ shown in Figs. 3 and 4 have the characteristic peak found for ammonium salts. The $C_{\text {resid }}$ contains contributions from both the anisotropic thermal expansion and the rotational motion of the cation, and these two components cannot be separated without further information on the elastic constant tensor. The effect of deuteration on $C_{\text {resid }}$ is to increase the residual heat capacity at the peak from $46.34 \mathrm{~J} \mathrm{~K}^{-1} \mathrm{~mol}^{-1}$ to $56.54 \mathrm{~J} \mathrm{~K}^{-1} \mathrm{~mol}^{-1}$ without any measurable shift in the position of the peak. The absence of any shift in the temperature at which the peak is found is consistent with observations in other ammonium salts such as $\mathrm{NH}_{4} \mathrm{BF}_{4}$ and $\mathrm{ND}_{4} \mathrm{BF}_{4},{ }^{16}$ and with calculations of rotational heat capacities. ${ }^{17}$

One method for obtaining the rotational heat capacity of the ammonium ion is to use an alkali metal salt as a reference material, from which the lattice heat capacity of the ammonium salt can be deduced. This technique may be useful in cases where the thermal expansion coefficients of the ammonium salt are similar to those of the alkali metal salt, but it is clear from the present analysis that the contribution of thermal expansion, including anisotropy, will not cancel by subtraction if there is an appreciable difference in the thermal expansion tensors of the two salts. Analyses using the potassium salts as reference materials have been published for the cases of $\mathrm{NH}_{4} \mathrm{ReO}_{4},{ }^{18}$ in which thermal expansion is highly anisotropic, ${ }^{19}$ and $\mathrm{NH}_{4} \mathrm{ClO}_{4},{ }^{20}$ in which one of the thermal expansion coefficients is actually negative. ${ }^{21}$ It appears that the rotational heat capacities determined in those cases should be interpreted with caution.

Until the contribution of thermal expansion can be reliably separated from the rotational heat capacity of the ammonium ion, it does not seem to be profitable to try to fit theoretical models of rotational motion to experiment. However, the influence of ammonium ions on thermal expansion properties $^{22}$ is at least as interesting as their influence on the heat capacity. Experimental studies to obtain the elastic constants of crystals in support of thermodynamic measurements should be initiated. Elastic constants for crystals that are rotationally disordered are especially needed. 


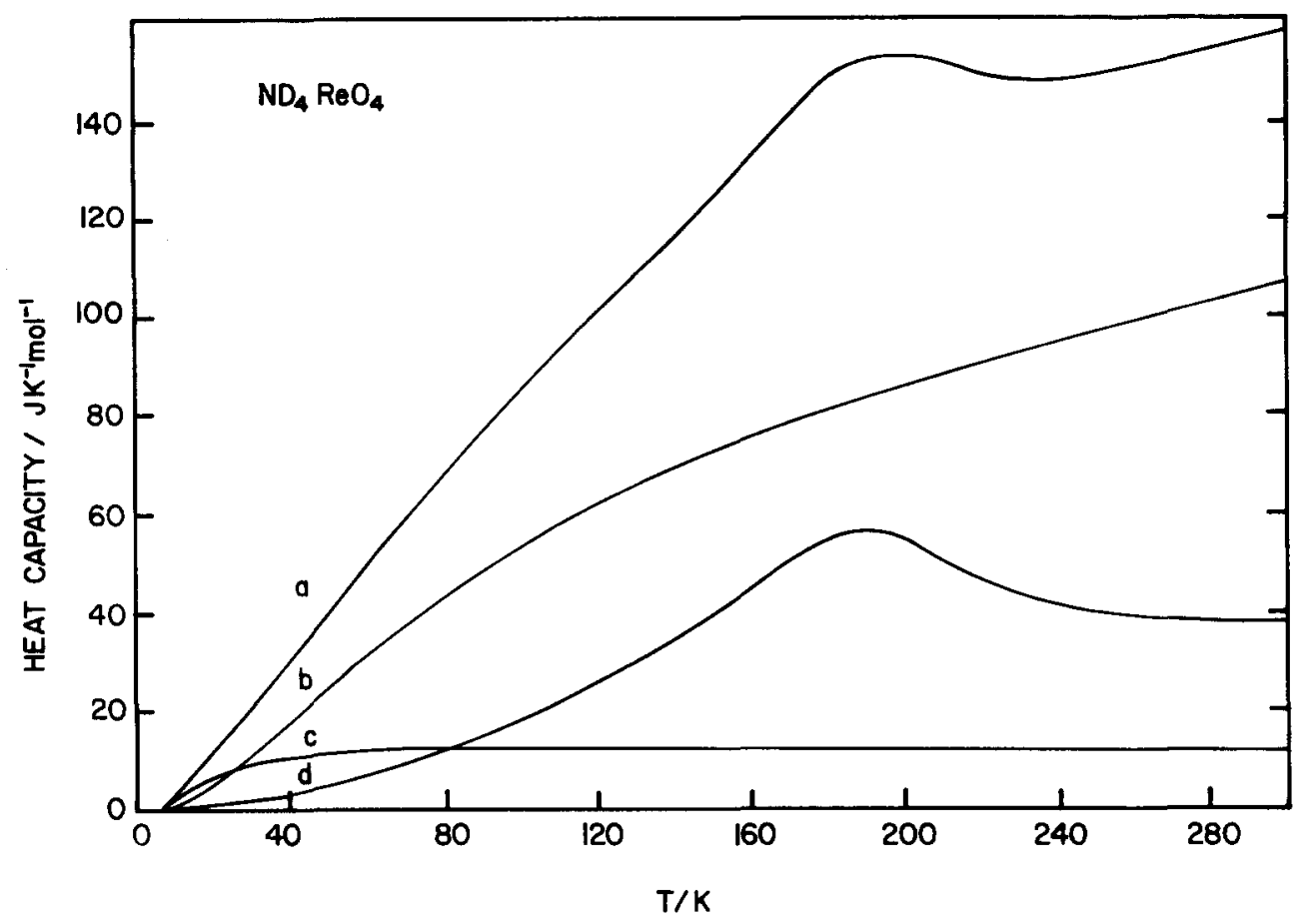

FIG. 4. Molar heat capacity of $\mathrm{ND}_{4} \mathrm{ReO}_{4}$. Curves: $\mathrm{a}=$ experimental (Ref. 3 ), b = vibrational contribution from internal + external optical modes of $\mathrm{ND}_{4}{ }^{+}$and $\mathrm{ReO}_{4}{ }^{-}$ and librational from external modes of $\mathrm{ReO}_{4}{ }^{-} ; \mathrm{c}=$ lattice contribution from $\mathrm{ND}_{4}^{+}$and $\mathrm{ReO}_{4}^{-}$(Debye heat capacity for acoustic modes), $\mathrm{d}=$ residual heat capacity $C_{\text {resid }}$ $=C_{\text {exp }}-C_{\text {vib }}-C_{\text {lat }}=\left(C_{p}-C_{\epsilon}\right)$ $+C_{\text {rot }}$ (see the text for full discussion of vibrational and lattice contributions).

TABLE IV. Heat capacity analysis for $\mathrm{ND}_{4} \mathrm{ReO}_{4} \cdot C_{\text {exp }}$, smoothed experimental molar heat capacity; $C_{\text {vib }}$, estimated contribution from internal optical modes of $\mathrm{ND}_{4}{ }^{+}$and $\mathrm{ReO}_{4}{ }^{-}$ions and all external optical modes except librational modes of $\mathrm{NH}_{4}{ }^{+} ; C_{\text {lib }}$, contribution from librational modes of $\mathrm{ND}_{4}{ }^{+}$ions; $C_{\text {lat }}$, lattice contribution from of $\mathrm{ND}_{4}{ }^{+}$and $\mathrm{ReO}_{4}{ }^{-}$(Debye heat capacity for acoustic modes) $C_{\text {resid }}=C_{\text {exp }}-C_{\text {vib }}-C_{\text {lat }}=C_{p}-C_{\epsilon}+C_{\text {rot }}$ (see the text).

\begin{tabular}{|c|c|c|c|c|c|c|}
\hline $\begin{array}{c}T \\
(\mathrm{~K})\end{array}$ & $\begin{array}{c}C_{\exp } \\
\left(\mathrm{J} \mathrm{K}^{-1} \mathrm{~mol}^{-1}\right)\end{array}$ & $\begin{array}{c}C_{\mathrm{vib}} \\
\left(\mathrm{J} \mathrm{K}^{-1} \mathrm{~mol}^{-1}\right)\end{array}$ & $\begin{array}{c}C_{\mathrm{lib}} \\
\left(\mathrm{J} \mathrm{K}^{-1} \mathrm{~mol}^{-1}\right)\end{array}$ & $\begin{array}{c}C_{\mathrm{exp}}-C_{\mathrm{vib}}-C_{\mathrm{lib}} \\
\left(\mathrm{J} \mathrm{K} \mathrm{K}^{-1} \mathrm{~mol}^{-1}\right)\end{array}$ & $\begin{array}{c}C_{\text {lat }} \\
\left(\mathrm{J} \mathrm{K}^{-1} \mathrm{~mol}^{-1}\right)\end{array}$ & $\begin{array}{c}C_{\text {resid }} \\
\left(\mathrm{J} \mathrm{K}^{-1} \mathrm{~mol}^{-1}\right)\end{array}$ \\
\hline 10 & 2.25 & 0.26 & 0.00 & 1.99 & 1.99 & 0.00 \\
\hline 20 & 11.25 & 3.80 & 0.00 & 7.45 & 6.71 & 0.74 \\
\hline 30 & 20.85 & 9.76 & 0.16 & 10.93 & 9.28 & 1.81 \\
\hline 40 & 30.20 & 16.85 & 0.98 & 12.37 & 10.51 & 2.84 \\
\hline 50 & 40.15 & 24.08 & 2.64 & 13.42 & 11.16 & 4.91 \\
\hline 60 & 49.50 & 30.93 & 4.83 & 13.74 & 11.54 & 7.03 \\
\hline 70 & 58.30 & 37.26 & 7.15 & 13.88 & 11.78 & 9.26 \\
\hline 80 & 67.15 & 43.12 & 9.36 & 14.67 & 11.94 & 12.10 \\
\hline 90 & 76.00 & 48.53 & 11.34 & 16.14 & 12.05 & 15.43 \\
\hline 100 & 83.75 & 53.50 & 13.06 & 17.19 & 12.12 & 18.12 \\
\hline 110 & 91.90 & 58.07 & 14.53 & 19.31 & 12.18 & 21.65 \\
\hline 120 & 99.90 & 62.23 & 15.78 & 21.89 & 12.23 & 25.44 \\
\hline 130 & 107.80 & 66.04 & $\ldots$ & $\ldots$ & 12.26 & 29.50 \\
\hline 140 & 115.80 & 69.52 & $\cdots$ & $\ldots$ & 12.29 & 33.99 \\
\hline 150 & 124.30 & 72.72 & $\ldots$ & $\ldots$ & 12.32 & 39.27 \\
\hline 160 & 132.60 & 75.69 & $\ldots$ & $\ldots$ & 12.33 & 44.58 \\
\hline 170 & 140.80 & 78.46 & $\cdots$ & $\ldots$ & 12.35 & 49.99 \\
\hline 180 & 148.10 & 81.08 & $\ldots$ & $\ldots$ & 12.36 & 54.65 \\
\hline 190 & 152.50 & 83.58 & $\cdots$ & $\ldots$ & 12.37 & 56.54 \\
\hline 200 & 153.40 & 85.98 & $\ldots$ & $\ldots$ & 12.38 & 55.14 \\
\hline 210 & 151.80 & 88.30 & $\ldots$ & $\ldots$ & 12.39 & 51.11 \\
\hline 220 & 149.50 & 90.56 & $\ldots$ & $\ldots$ & 12.40 & 46.54 \\
\hline 230 & 148.20 & 92.77 & $\cdots$ & $\cdots$ & 12.41 & 43.02 \\
\hline 240 & 148.30 & 94.94 & $\ldots$ & $\ldots$ & 12.41 & 40.95 \\
\hline 250 & 149.10 & 97.07 & $\cdots$ & $\ldots$ & 12.42 & 39.62 \\
\hline 260 & 150.50 & 99.16 & $\ldots$ & $\ldots$ & 12.42 & 38.92 \\
\hline 270 & 152.30 & 101.23 & $\cdots$ & $\ldots$ & 12.42 & 38.65 \\
\hline 280 & 154.00 & 103.26 & $\cdots$ & $\ldots$ & 12.43 & 38.31 \\
\hline 290 & 155.90 & 105.26 & $\cdots$ & $\ldots$ & 12.43 & 38.21 \\
\hline 300 & 157.90 & 107.23 & $\ldots$ & $\ldots$ & 12.43 & 38.23 \\
\hline
\end{tabular}




\section{ACKNOWLEDGMENTS}

One of us (R. J. C. B.) gratefully acknowledges the financial support by the Natural Sciences and Engineering Research Council of Canada. Another of us (R. D. W.) gratefully acknowledges the financial support by the Department of National Defense (Canada). Discussions with Dr. H. F. Shurvell and with Dr. D. Smith are gratefully acknowledged.

'R. D. Weir and L. A. K. Staveley, J. Chem. Phys. 73, 1386 (1980).

${ }^{2}$ D. Smith, J. Chem. Phys. 78, 6238 (1983).

${ }^{3}$ R. J. C. Brown, J. E. Callanan, R. D. Weir, and E. F. Westrum, Jr., J. Chem. Thermodyn. 18, 787 (1986).

${ }^{4}$ R. J. C. Brown, J. G. Smeltzer, and R. D. Heyding, J. Magn. Reson. 74, 269 (1976).

${ }^{5}$ S. L. Segel, H. Karlson, T. Gustavson, and K. Edstrom, J. Chem. Phys. 82, 1611 (1985).

${ }^{6} \mathrm{M}$. Born and K. Huang, Dynamical Theory of Crystal Lattices (Oxford University, Oxford, 1954), p. 282.

'A. I. Kitaigorodsky, Molecular Crystals and Molecules (Academic, New York, 1973), p. 342.
${ }^{8}$ D. C. Wallace, Thermodynamics of Crystals (Wiley, New York, 1972), p. 26.

${ }^{9} \mathrm{G}$. Simmons and H. Wang, Single Crystal Elastic Constants and Calculated Aggregate Properties (MIT Cambridge, 1971)

${ }^{10} \mathrm{~J}$. Korppi-Tommola, R. J. C. Brown, H. F. Shurvell, and O. Sala, J. Raman Spectrosc. 11, 363 (1981).

"J. Korppi-Tommola, V. Devarajan, R. J. C. Brown, and H. F. Shurvell, J. Raman Spectrosc. 7, 96 (1978)

${ }^{12}$ Y. S. Park, H. F. Shurvell, and R. J. C. Brown, J. Raman Spectrosc. (in press).

4

${ }^{13}$ R. H. Busey and O. L. Keller, J. Chem. Phys. 41, 215 (1964).

${ }^{14}$ K. Ulbricht and H. Kreigsman, Z. Anorgan. Chem. 358, 193 (1968).

${ }^{15}$ R. A. Johnson, M. T. Rogers, and G. E. Leroi, J. Chem. Phys. 56, 789 (1972).

${ }^{16} \mathrm{C}$. C. Stephenson, R. S. Orehotsky, and D. Smith, Proceedings of Thermodynamic Symposium, edited by $\mathrm{K}$. Shaeffer (AZ-Werbung-Weber Druck, Heidelberg, 1967), Vol. 2, p. 1

${ }^{17}$ D. Smith, Pennsylvania State University, Hazelton, Pa 18201 (private communication, 1986).

${ }^{18}$ M. A. White, N. H. Green, and L. A. K. Staveley, J. Chem. Thermodyn. 13, 283 (1981).

${ }^{19}$ A. P. Caron, D. J. Huettner, J. L. Ragle, L. Sherk, and T. R. Stengle, J. Chem. Phys. 47, 2577 (1967).

${ }^{20}$ E. F. Westrum, Jr. and B. H. Justice, J. Chem. Phys. 50, 5083 (1969).

${ }^{21}$ C. S. Choi, H. J. Prask, and E. Prince, J. Chem. Phys. 61, 3523 (1974).

${ }^{22}$ D. Smith, J. Chem. Phys. 79, 2995 (1983). 